Çukurova Üniversitesi Mühendislik Mimarlık Fakültesi Dergisi, 30(1), 215-221ss., Haziran 2015

Çukurova University Journal of the Faculty of Engineering and Architecture, 30(1), pp. 215-221, June 2015

\title{
İnşaat Sektöründe Mobbing Sorunsalı
}

\author{
Olcay GENÇ ${ }^{* 1}$, Ercan ERDIŞ ${ }^{1}$ \\ ${ }^{1}$ İskenderun Teknik Üniversitesi, İnşaat Fakültesi, İnşaat Mühendisliği Bölümü, Hatay
}

Geliş tarihi: $18.05 .2015 \quad$ Kabul tarihi: 24.06 .2015

\section{Özet}

Mobbing işyerlerinde ast, üst ayrımı olmaksızın tüm çalışan/çalışanların kasıtlı, sistemli ve sürekli olarak, açıktan veya gizli bir biçimde gerçekleştirebileceği, kişiyi yıldırma, pasifize etme ve işten uzaklaştırma amacını güden, mağdurun/mağdurların kişilik değerlerine, mesleki durumlarına, sosyal ilişkilerine veya sağlıklarına zarar veren tüm olumsuz tutum ve davranışlardır. Günümüzde çalışma hayatında oldukça sık karşılaşılan, ancak çalışanlar arasında ne olduğu tam anlamıyla pek bilinmeyen bir kavram olan mobbing, sosyal yaşantının olduğu her yerde karşımıza çıkmakta ve genellikle çözümü olmayan bir sorun olarak karşılanmaktadır. Bu çalışmanın amacı da, inşaat mühendisleri özelinde teknik elemanların mobbing kavramını algılama düzeylerinin ve karşılaştıkları mobbing tarzı durumlar karşısında farkındalıklarının ölçülmesi, maruz kaldıklarında verdikleri tepkilerin analiz edilmesi ve bu olumsuz tutum ve davranışları nasıl minimize etmeleri gerektiği ile ilgili çözüm önerilerini saptamaktır. Bu kapsamda Adana ili özelinde, inşaat mühendislerine, Adana İnşaat Mühendisleri Odası vasıtasıyla online olarak oluşturulan bir anket uygulanmış ve 111 kişiden alınan veriler toplanıp analiz edilmiştir. Sonuçlar, literatür ve anket bulguları ışığında değerlendirilmiştir.

Anahtar Kelimeler: Mobbing, Psikolojik taciz, Psikolojik terör

\section{Problematical of Mobbing in Construction Industry}

\begin{abstract}
Mobbing is a group of negative behaviors that is performed by either superiors or subordinates against each other openly or confidentially through systematically and constantly at a workplace. The main aims of this behavior are to pacifism, alienate and send the victim away from the workplace. Mobbing harms the victim'personality, occupational situation, social relations and finally health. Mobbing, which is quite commonly heard in work life but as a concept is not known exactly among employees, is encountered everywhere in the social life and thought it is an unsolvable problem. This study examines mobbing awareness of civil engineers who work in Adana Region of Turkey, analyses their behaviors when they experience it, and obtain solution suggestions against it. To achieve this objective, a web-based survey has been prepared and delivered to 111 civil engineers via their chamber and results were analyzed.
\end{abstract}

Keywords: Mobbing, Psychological violence, Psychological terror

\footnotetext{
* Yazışmaların yapılacağı yazar: Olcay GENÇ, İskenderun Teknik Üniversitesi, İnşaat Fakültesi, İnşaat Mühendisliği Bölümü, İskenderun, Hatay.genc_olcay@hotmail.com
} 


\section{GíRiș}

Latince "mobile vulgus" sözcügüunden gelen "mobbing" kelimesi; rahatsılılk verme, taciz etme ve her türlü fiziksel ve ruhsal yorgunluğa neden olan olumsuz tutum ve davranışlar gibi anlamlar taşımaktadır. İngilizce 'de ise "mob" eylemi, bir yerde toplanmak, saldırmak ve rahatsız etmek anlamında kullanılmaktadır.

Mobbing kavramı zaman zaman, benzer kavram olan "Bullying" ile karıştırılmaktadır. Leymann [1] "Mobbing", Adams ve Crawford [2] "Bullying" kelimesini birlikte çalışan kişilerin, belli bir kişiye karşı, tekrarlanan agresif ve zararlı davranışlarını tanımlamak için kullanmıştır. Leymann [3] bu konudaki terminolojik karışıklığın ortadan kalkması için; okul işletmeleri için "bullying", işyerleri için ise "mobbing" kelimesini önermiş, mobbingin daha sofistike davranışlarla karakterize edilmesi gerektiğini belirtmiştir. İçinde fiziksel cebri de barındıran bir zorbalığı ifade eden bullying, okullarda uygulanan ve 'sürekli kusur bulma'veya 'bireyi küçük düşürme'anlamında da kullanılmaktadır.

Mobbing davranışı bireyler arasında gerçekleşen ve bir takım olumsuz etkilere sahip olan bir çeşit negatif iletişim şeklidir. Kişiyle sıklıkla alay etmek, sözünü kesmek, yalancı olduğunu ima etmek ve hakkında dedikodu yaymak bu davranışa örnek olarak verilebilir [4]. Leymann [1] mobbingi; psikolojik şiddet ve psiko-terör olarak adlandırırken, bir veya birden fazla kişi tarafından, diğer kişi ya da kişilere yönelik gerçekleştirilen; sistematik bir biçimde devam eden düşmanca ve etik dışı davranışlar olarak tanımlamıştır.

Mobbing kavramı, ilk olarak 1960'lı yıllarda Avusturyalı bilim adamı Lorenz tarafindan hayvanların kendi aralarında ya da bir yabancıya karşı uyguladıkları taciz davranışı şeklinde tanımlanmıştır [5]. Sonraki yıllarda ise İsveç'li bilim adamı Heinemann [6], okul yaşantısında öğrenciler arasında görülen zorbalık ve taciz olaylarını ele almıştır. Heinemann [6], İsveç’te "Mobbing: Group Violence among Children" adlı kitabında; çocuklar arasında görülen zorbalık ve şiddet hareketlerinin önünün alınamaması durumunda, mobbing nedeniyle mağdurların ümitsizlik ve korku gibi nedenlerle, intihara yönelebileceğini vurgulamıştır [7]. 1980 ve 1990'lı yıllarda ise Leymann, mobbing terimini iş hayatındaki baskı, şiddet ve yıldırma hareketlerini tanımlamak için kullanmıştır $[1,3,5]$.

Mobbing işyerlerinde ast, üst ayrımı olmaksızın tüm çalışan/çalışanların kasıtlı, sistemli ve sürekli olarak, açıktan veya gizli bir biçimde gerçekleştirebileceği, kişiyi yıldırma, pasifize etme ve işten uzaklaştırma amacını güden, mağdurun/mağdurların kişilik değerlerine, mesleki durumlarına, sosyal ilişkilerine veya sağlıklarına zarar veren tüm olumsuz tutum ve davranışlardır [8].

İşyerinde karşılaşılan her türlü olumsuz davranış mobbing olarak algılanmamalıdır. İşyerlerinde; üstler tarafından astlarına, astlar tarafindan üstlere de uygulanabilen ya da eşitler arasında da gerçekleşmesi mümkün olan mobbing'den söz edebilmek için; kasıtlı, sistemli ve sürekli bir şekilde gizli veya açıktan yapılması, yıldırma, pasifize etme ve işten uzaklaştırma amacını gütmesi ve mağdurun kişiliğinde, mesleki durumunda veya sağlığında bir zararın ortaya çıkmış olması gerekir.

Literatürde bireysel anlamda bilinç düzeyinin henüz yeterince gelişmediği ve kurumsal hafızanın oluşmadığı verilen cevaplardan anlaşılmaktadır. [8]. İşyerlerinde psikolojik tacize maruz kaldığını düşünen kişi öncelikle içinde bulunduğu durumu sağlıklı bir şekilde değerlendirerek, yaşanılan sürecin işyerinde psikolojik taciz olduğu yönünde kanaate varırsa aşağıda belirtilen hususlara dikkat etmelidir [8]:

- Kişi, öncelikle çatışmadan kaçınılmalı ve sakin olmalıdir.

- Psikolojik taciz üst yönetim tarafindan gerçekleştirilmiyorsa konuyu üst yönetime uygun bir şekilde iletmelidir.

- Psikolojik taciz üst yönetim tarafından gerçekleştiriliyorsa, Çalışma ve Sosyal Güvenlik Bakanlığının İletişim Merkezi Alo 170'i arayarak, işyerlerinde psikolojik taciz konusunda uzman psikologlardan ve 
gerekiyorsa uzman doktorlardan destek almalidir.

- Psikolojik tacize uğradığını kanıtlayacak yazışma, not, mesaj, e-posta gibi bilgi ve belgeleri saklamalidır.

- Yaşanılan psikolojik taciz sürecine ilişkin günlük tutmalıdır.

- Yaşanılan sürece şahit olan/olabilecek çalışma arkadaşları ile görüşülmelidir.

- Kişi, gerekirse üyesi olduğu sendikadan destek talep etmelidir.

- Kişi, ihtiyaç duyması halinde ise hukuki destek almalıdır.

- İşyerlerinde psikolojik tacize maruz kalan kişi sorunu işyerinde çözemediği takdirde, kanıtlarıyla birlikte konuyu yargıya taşımalıdır.

İşletmelerin bulundukları sektörde, nitelik ve nicelik olarak farklı özelliklere sahip olmaları, kurumsal olarak mobbingle mücadele yönetmelerinde de farklılıklar göstermesine neden olabilmektedir. İşletmeler, işyerinde mobbing unsurlarının ortaya çıkması halinde, kamuoyundaki itibarları ve marka değerlerini zarara uğratmamak için kurum olarak aşağıda belirtilen önlemleri öncelikle hayata geçirmelidirler [8].

- İşyerleri, öncelikle kurum içinde mobbingi önleyici politikalar geliştirmelidir.

- İşyerlerinde mobbing konusunda tehlikeleri anlatan broşürler dağıtılmalı, bu konuda çalışanlara ve yöneticilere yönelik eğitim ve bilinçlendirme çalışmaları yapılmalıdır.

- İşyerleri, kendi işletme yapısına uygun olarak, mobbing olaylarının incelenmesi için yöntemler geliştirmeli, işyerinde mobbinge teşebbüs eden kişiler için disiplin cezaları ve rehabilitasyon önlemleri alınmalıdır.

- İşyerlerinde mobbing şikâyetleri dikkate alınarak, adil çözüm yolları geliştirilmelidir.

- İşyerlerinde mobbingi önlemek için alınacak tedbirlerde, bu yöndeki iddiaların araştırılması ve soruşturulmasında "gizliliğin korunmasına" özel hassasiyet gösterilmelidir.

- Toplu iş sözleşmesi, iş sözleşmesi veya işyeri yönetmeliklerine konuyla ilgili hükümler konulmalıdır.
Bu çalışmanın amacı, Adana ili özelinde, sektörde görev yapan inşaat mühendislerinin; mobbing kavramını algılama düzeylerinin ve karşılaştıkları mobbing tarzı durumlar karşısındaki farkındalıklarının ölçülmesi, mobbinge maruz kaldıklarında verdikleri tepkilerin analiz edilmesi ve bu olumsuz tutum ve davranışları nasıl minimize etmeleri gerektiği ile ilgili çözüm önerilerini saptamaktır. Bu kapsamda, çalışmada 8 sorudan oluşan online bir anket oluşturulmuştur. Anket Adana İnşaat Mühendisleri Odası vasitasıyla inşaat mühendislerine online olarak ulaştırılarak veriler toplanmıştır. Sonuçlar, literatür ve anket bulguları 1şı ğında değerlendirilmiştir.

\section{MATERYAL VE METOT}

Üç bölümden oluşan web tabanlı anketin ilk bölümünde; katılımcının mobbing hakkında bilgisi olup olmadığı, mobbinge maruz kalıp kalmadığı ve çalıştıkları kurumda kimler tarafından mobbinge maruz kaldığını ölçen üç soru yer almaktadır. Anketin ikinci bölümünde ise sadece mobbinge maruz kalanların cevaplandıracağı; mobbinge maruz kalan inşaat mühendislerinin aile ve sosyal hayatının nasıl değiştiği analiz edilmiştir. Anketin üçüncü bölümünde inşaat mühendislerinin bireysel olarak mobbinge maruz kaldıklarında yaşadıklarının analiz edildiği soruya yer verilmiştir. Dördüncü bölümde ise inşaat mühendislerinin mobbinge maruz kaldıklarında/kalmaları durumunda verdikleri bireysel tepkilerin dağılımı incelenmiş ve son bölümde inşaat mühendislerinin bireysel olarak mobbinge maruz kaldıklarında verdikleri tepkilere bağlı olarak elde ettikleri kazanımlar veya kayıplar analiz edilmiştir.

Anket linki Adana İnşaat Mühendisleri Odası vasıtasıyla inşaat mühendislerine ulaştırılmıştır. Link, bir kişinin anketi birden fazla kez yanıtlamasını engellemek amaciyla her bilgisayarda yalnızca bir kez çalışacak şekilde programlanmıştır. Araştırmanın evreni Adana ili özelinde çalışan inşaat mühendisleri olup, örnek uzayı ise 111 adet inşaat mühendisidir. 


\section{ARAŞTIRMA BULGULARININ DEĞERLENDİRILMESI}

Çalışmanın bulgular kısmı, inşaat mühendislerinin mobbing kavramını algılama düzeylerini tespit etmek, mobbinge maruz kalan kişilerin verdikleri tepkilerin analiz edilmesi ve bu olumsuz tutum ve davranışları nasıl minimize etmeleri gerektiği ile ilgili anket sonuçlarının değerlendirilmesi ve yorumlanmasından oluşmaktadır.

\section{1. İnşaat Mühendislerinin Mobbing Kavramına Olan Farkındalığı, Mobbinge Maruz Kalma Düzeyleri ve Çalıştıkları Kurumda İnşaat Mühendislerine Mobbing Uygulayan Kişi/Gruplar}

Çizelge 1 incelendiğinde katılımcıların \%18'inin daha önce mobbing konusunda bilgisinin olmadığ anlaşılmaktadır. Mobbing ya da psikolojik taciz kelimelerini daha önce duymamış olanların \%40'ının ise aslında geçmişte yaşadıkları olumsuz durumları mobbing olarak değerlendirmeleri inşaat mühendislerinin bu konudaki bilinç düzeyinin eksikliğini gösteren bir sonuç olarak da değerlendirilebilir.

Çizelge 1. İnşaat mühendislerinin mobbing kavramına olan farkındalığ

\begin{tabular}{|c|c|c|}
\hline \multirow[t]{2}{*}{ Sorular } & \multicolumn{2}{|c|}{$\begin{array}{c}\text { Verilen } \\
\text { Cevapların } \\
\text { Frekansı ve } \\
\text { Yüzdesi } \\
\end{array}$} \\
\hline & $\mathrm{f}$ & $\%$ \\
\hline $\begin{array}{l}\text { Daha önce mobbing/ } \\
\text { psikolojik taciz } \\
\text { düzcüklerini } \\
\text { duynuz mu? }\end{array}$ & & \\
\hline $\begin{array}{l}\text { Evet } \\
\text { Hayir }\end{array}$ & $\begin{array}{l}91 \\
20\end{array}$ & $\begin{array}{l}82,0 \\
18,0\end{array}$ \\
\hline
\end{tabular}

Çizelge 2 incelendiğinde katılımcıların çoğunun $(\% 57,7)$ mobbinge maruz kaldığı görülmüştür.
Çizelge 2. İnşaat mühendislerinin mobbinge maruz kalma düzeyleri

\begin{tabular}{|c|c|c|}
\hline \multirow[t]{2}{*}{ Sorular } & \multicolumn{2}{|c|}{$\begin{array}{l}\text { Verilen } \\
\text { Cevapların } \\
\text { Frekansı ve } \\
\text { Yüzdesi }\end{array}$} \\
\hline & $\mathrm{f}$ & $\%$ \\
\hline $\begin{array}{l}\text { Önceki veya șu anki çalıștığınız } \\
\text { ortamda mobbinge maruz kalmıs } \\
\text { olduğunuzu düșünüyormusunuz? }\end{array}$ & & \\
\hline $\begin{array}{l}\text { Evet } \\
\text { Hayır }\end{array}$ & $\begin{array}{l}64 \\
47\end{array}$ & $\begin{array}{l}57,7 \\
42,3\end{array}$ \\
\hline
\end{tabular}

Çizelge 3 incelendiğinde ise inşaat mühendislerinin en çok üstleri tarafından mobbinge maruz kaldığg görülmektedir $(\% 87,5)$.

Çizelge 3. Çalıştıkları kurumda inşaat mühendislerine mobbing uygulayan kişi/gruplar

\begin{tabular}{|c|c|c|}
\hline \multirow[t]{2}{*}{ Sorular } & \multicolumn{2}{|c|}{$\begin{array}{c}\text { Verilen } \\
\text { Cevapların } \\
\text { Frekansı ve } \\
\text { Yüzdesi }\end{array}$} \\
\hline & $\mathrm{f}$ & $\%$ \\
\hline $\begin{array}{l}\text { Kimler tarafindan psikolojik } \\
\text { tacize uğradınız? }\end{array}$ & & \\
\hline $\begin{array}{l}\text { Üstlerim (İşverenler, } \\
\text { patronlar, yöneticiler vb.) }\end{array}$ & 56 & 87,5 \\
\hline Astlarım & 12 & 18,8 \\
\hline $\begin{array}{l}\text { Eşitim olan } \\
\text { meslekdaşlarım/Mesai } \\
\text { arkadaşlarım }\end{array}$ & 23 & 35,9 \\
\hline
\end{tabular}

\subsection{Mobbinge Maruz Kalan İnşaat Mühendislerinin Aile ve Sosyal Hayat İlişkisi}

Çizelge 4 incelendiğinde inşaat mühendislerinin \%54,7'si işteki sıkıntılarını ailesine ve sosyal çevresine yansitmamaya çalışmasına rağmen, $\% 53,1$ ' $\mathrm{i}$ ise evde ve sosyal çevrede daha agresif bir insan olduğunu belirtmişlerdir. 
Çizelge 4. Mobbinge maruz kalan inşaat mühendislerinin aile ve sosyal hayat ilişkisi

\begin{tabular}{|c|c|c|}
\hline \multirow[t]{2}{*}{ Sorular } & \multicolumn{2}{|c|}{$\begin{array}{c}\text { Verilen } \\
\text { Cevapların } \\
\text { Frekans1 ve } \\
\text { Yüzdesi }\end{array}$} \\
\hline & $\mathrm{f}$ & $\%$ \\
\hline $\begin{array}{l}\text { Psikolojk tacize uğradĭ̆ınız } \\
\text { dönemde aile ve sosyal hayatınız } \\
\text { nasıl etkilendi? }\end{array}$ & & \\
\hline $\begin{array}{l}\text { Evde ve sosyal çevrede daha agresif } \\
\text { bir insan oldum. }\end{array}$ & 34 & 53,1 \\
\hline $\begin{array}{l}\text { Eşimle ve çocuklarımla daha sık } \\
\text { tartışmaya ve onlara daha sert } \\
\text { davranmaya başladım. }\end{array}$ & 15 & 23,4 \\
\hline Ailem bana destek oldu. & 22 & 34,4 \\
\hline $\begin{array}{l}\text { İşteki sıkıntılarımı aileme ve sosyal } \\
\text { çevreme yansıtmamaya çalıştım. }\end{array}$ & 35 & 54,7 \\
\hline
\end{tabular}

\subsection{Inşaat Mühendislerinin Bireysel Olarak Mobbinge Maruz Kaldıklarında Yaşadıkları}

Çizelge 5 incelendiğinde mobbinge maruz kalan inşaat mühendislerinin $\% 56,3$ 'ünün yaşadıkları bu tarz olumsuz tutum ve davranışlar karşısında üzüntü yaşadıkları ve \%34,4'ünün ise psikolojisinin bozulduğu anlaşılmıştır.

Çizelge 5. İnşaat mühendislerinin bireysel olarak mobbinge maruz kaldıklarında yaşadıkları

\begin{tabular}{|c|c|c|}
\hline \multirow[t]{2}{*}{ Sorular } & \multicolumn{2}{|c|}{$\begin{array}{c}\text { Verilen } \\
\text { Cevapların } \\
\text { Frekansi ve } \\
\text { Yüzdesi }\end{array}$} \\
\hline & $\mathrm{f}$ & $\%$ \\
\hline \multicolumn{3}{|l|}{ Size uygulanan psikolojik taciz } \\
\hline \multicolumn{3}{|l|}{ hangisi gerçeklești? } \\
\hline İşime son verildi. & 8 & 12,5 \\
\hline Görev yerim değisti. & 9 & 14,1 \\
\hline Psikolojim bozuldu. & 22 & 34,4 \\
\hline Psikolojik tedavi gördüm. & 3 & 4,7 \\
\hline $\begin{array}{l}\text { Psikosomotik hastalıklar (tansiyon, } \\
\text { şeker, mide hastalığı, nedensiz baş } \\
\text { ağrısı ve benzerleri) gelişti. }\end{array}$ & 8 & 12,5 \\
\hline $\begin{array}{l}\text { Psikolojim bozulmadı ama } \\
\text { üzüldüm. }\end{array}$ & 36 & 56,3 \\
\hline
\end{tabular}

\section{4. İnşaat Mühendislerinin Mobbinge Maruz Kaldıklarında/Kalmaları Durumunda Verdikleri Bireysel Tepkiler}

Çizelge 6'da ise inşaat mühendislerinin \%62,2'sinin mobbinge maruz kaldıklarında/kalmaları durumunda öncelikle çatışmadan uzak durarak sakin kalmaya çalıștıkları, \%40,5'inin konuyu üst yönetime/kurum içinde yetkili kişilere uygun bir şekilde ilettiği/ileteceği, \%39,6'sının yaşanılan sürece şahit olan/olabilecek çalışma arkadaşları ile görüşmeler yapacağ1/yaptığ 1 ve \%31,5'inin ise istifa ettiği/edeceği anlaşılmaktadır.

Katılımcıların yarısından fazlasının mobbinge uğradıklarını belirtmesine rağmen, çalıştıkları işyerlerinde psikolojik tacizi önleyici politikalar geliştirilmediğini, Mobbing ile Mücadele Derneğini ve diğer kamu kuruluşlarını, mobbinge maruz kaldıklarında, kendilerine destek verebilecek veya kendilerini koruyacak bir unsur olarak görmediklerini belirtmeleri, yada tıbbi destek/uzman desteği almadıklarını beyan etmeleri kurumsal veya bireysel anlamda konunun yeterince anlaşılmadığını göstermektedir. $\mathrm{Bu}$ konuda bireysel anlamda bilinç düzeyinin henüz yeterince gelişmediği ve kurumsal hafızanın oluşmadığı verilen cevaplardan anlaşılmaktadır.

\subsection{Inşaat Mühendislerinin Bireysel Olarak Mobbinge Maruz Kaldıklarında Meydan Gelen Tepki-Sonuç İlişkisi Sonucu Kazanım ve Kayıpları}

İnşaat mühendislerinin yaşanılan psikolojik taciz sonrasinda mobbing konusunda yeterince bilgi sahibi olmamaları, hatta yaşadıkları olayları mobbing olarak değerlendirmemeleri nedeniyle yalnızca \%3,1'lik bir kısmının şikayet edip mobbingi durdurdukları, \%43,8'inin ise olay karşısında bir şey yapmadığını ya da yapmak istemediği Çizelge 7'den anlaşılmaktadır.

\section{SONUÇLAR VE ÖNERILER}

Amac1, Adana bölgesinde çalışan inşaat mühendislerinin çeşitli nedenlerle karşılaştıkları 
Çizelge 6. İnşaat mühendislerinin mobbinge maruz kaldıklarında/kalmaları durumunda verdikleri bireysel tepkilerin dağılımı

\begin{tabular}{|c|c|c|}
\hline \multirow[t]{2}{*}{ Sorular } & \multicolumn{2}{|c|}{$\begin{array}{l}\text { Verilen } \\
\text { Cevapların } \\
\text { Frekansı ve } \\
\text { Yüzdesi }\end{array}$} \\
\hline & $\mathrm{f}$ & $\%$ \\
\hline $\begin{array}{l}\text { Mobbing'e maruz } \\
\frac{\text { kaldıysanız/kalsaydınız nasıl bir tepki }}{\text { verdiniz/verirdiniz? (birden fazla }} \\
\text { seçenek ișaretleyebilirsiniz) }\end{array}$ & & \\
\hline $\begin{array}{l}\text { Bir şey yapmadım/yapmam. } \\
\text { İşyerimde psikolojik tacizi önleyici } \\
\text { politikalar geliştirilmiş durumda. }\end{array}$ & 5 & $\begin{array}{l}4,5 \\
1,8\end{array}$ \\
\hline $\begin{array}{l}\text { Öncelikle çatışmadan kaçınarak, } \\
\text { sakin olmaya gayret ettim/ederim. } \\
\text { Konuyu üst yönetime/kurum icinde }\end{array}$ & 69 & 62,2 \\
\hline $\begin{array}{l}\text { yetkili kişilere uygun bir şekilde } \\
\text { ilettim/iletirim. } \\
\text { Psikolojik tacize } \\
\end{array}$ & 45 & 40,5 \\
\hline $\begin{array}{l}\text { kanıtlayacak yazışma, not, mesaj, e- } \\
\text { posta gibi bilgi ve belgeleri } \\
\text { oluşturdum/oluştururum. }\end{array}$ & 26 & 23,4 \\
\hline $\begin{array}{l}\text { Yaşanılan psikolojik taciz sürecine } \\
\text { ilişkin günlük tuttum/tutarım. }\end{array}$ & 3 & 2,7 \\
\hline $\begin{array}{l}\text { Yaşanılan ş̈rece şahit } \\
\text { olan/olabilecek çalışma arkadaşlar ile } \\
\text { görüşmeler yaptım/yaparım. }\end{array}$ & 44 & 39,6 \\
\hline $\begin{array}{l}\text { Üyesi olduğum sendikadan destek } \\
\text { talep ettim/ederim. }\end{array}$ & 7 & 6,3 \\
\hline $\begin{array}{l}\text { BİMER'e (Başbakanlık İletişim } \\
\text { Merkezi) şikayet ettim/ederim. }\end{array}$ & 8 & 7,2 \\
\hline $\begin{array}{l}\begin{array}{l}\text { Diğer kamu kuruluşlarına şikayet } \\
\text { ettim/ederim } \\
\text { (Cumhurbaşkanlığı, } \\
\text { TBMM vb.) }\end{array}\end{array}$ & 0 & 0,0 \\
\hline Çalışma ve Sosyal Güvenlik & & \\
\hline Bakanlığının İletişim Merkezi Alo & & \\
\hline $\begin{array}{l}170 \text { 'i arayarak, işyerlerinde } \\
\text { psikolojik taciz konusunda uzman } \\
\text { psikologlardan destek aldım/alırım. }\end{array}$ & 2 & 1,8 \\
\hline $\begin{array}{l}\text { "Mobbing ile Mücadele Derneğine" } \\
\text { başvurdum/ başvururum. }\end{array}$ & 2 & 1,8 \\
\hline $\begin{array}{l}\text { Tıbbi destek/Uzman desteği } \\
\text { aldım/alırım. }\end{array}$ & 2 & 1,8 \\
\hline Hukuki destek aldım/alırım. & 17 & 15,3 \\
\hline İstifa ettim/ederim. & 35 & 31,5 \\
\hline $\begin{array}{l}\text { Başka yere/kuruma } \\
\text { istedim/ederim. }\end{array}$ & 7 & 6,3 \\
\hline $\begin{array}{l}\text { Psikolojik taciz yapanlara fiziksel } \\
\text { saldırıda bulundum/bulunurum. }\end{array}$ & 3 & 2,7 \\
\hline $\begin{array}{l}\text { Psikolojik taciz yapanlara psikolojik } \\
\text { saldırıda bulundum/bulunurum. }\end{array}$ & 24 & 21,6 \\
\hline
\end{tabular}

Çizelge 7. İnşaat mühendislerinin bireysel olarak mobbinge maruz kaldıklarında meydan gelen tepki-sonuç ilişkisi sonucu kazanım ve kayıpları

\begin{tabular}{cc} 
& Verilen \\
Sorular & Cevapların \\
& Frekans1 ve \\
& Yüzdesi \\
\cline { 2 - 2 } & $\mathrm{f} \quad \%$ \\
\hline
\end{tabular}

Size karșl yapilan psikolojik tacize

karșl verdiğiniz tepkiden sonuc

aldinız $m \imath$ ?

Dava açtım-Psikolojik tacizi

durdurdum

Dava actım-Sonuç alamadım $\quad 0 \quad 0,0$

Şikayet ettim-Psikolojik tacizi

durdurdum

Sikayet ettim-Sonuç alamadım $\quad 13 \quad 20,3$

Dava veya sikayet sürecim devam

etmektedir

$1 \quad 1,6$

Dava veya şikayet etmek istiyorum $\quad 1 \quad 1,6$

Çaresizim, elimden bir șey gelmez $\quad 19 \quad 29,7$

Bir şey yapmadım/yapmak $28 \quad 43,8$

istemiyorum

mobbing/psikolojik taciz hakkında farkındalığın ölçülmesi, maruz kaldıklarında bireysel olarak aile hayatı ve sosyal yaşamında verdikleri tepkilerin analiz edilmesi, bunun sonucundaki kazanım ve kayıplarının tespiti ve bu durumun minimize edilmesi ile ilgili çözüm önerilerini saptamak olan bu çalışmada, katılımcıların büyük çoğunluğunun aslında mobbinge maruz kaldığı anlaşılmıştır. Katılımcıların yarısı yaşanılan mobbing olayı sonrası evde ve sosyal çevrede daha agresif bir insan olduğunu ve psikolojisinin bozulduğunu belirtmiştir. Mobbinge maruz kalan bir çok çalışanın ise aslında yaşanılan psikolojik taciz karşısında çaresiz olduğunu ve bir şey yapmadığını belirtmesi, bir şeyler yapmaya çalışanların ise şikayetlerinden sonuç alamaması ve yaklaşık yarısının psikolojik taciz sonrasında işini bırakması, bu konuda katılımciların bireysel anlamda bilinç düzeyinin henüz yeterince gelişmediğini ve kurumsal hafızanın da oluşmadığını göstermektedir.

$\mathrm{Bu}$ çerçevede inşaat mühendislerinin mobbing karşısında bireysel mücadeleyi nasıl yapacakları 
yönündeki bilinç düzeyinin artırılması ve şirketlerinde, kurumsal anlamda mobbingle mücadele önlemlerinin nasıl alınacağı ile ilgili kurumsal hafizalarını geliştirmeleri gerekmektedir. $\mathrm{Bu}$ da ancak bu konudaki akademik çalışmaların sayısının ve niteliğinin artırılması ile mümkün olacaktır.

\section{KAYNAKLAR}

1. Leymann, H., 1990. Mobbing and Psychological Terror at Workplaces, Springer Publishing Company, pp. 119-126(8).

2. Adams, A.,Crawford, N., 1992. Bullying at work: How to confront and overcome it. London: Virago Press.

3. Leymann, H., 1996. The Content and Development of Mobbing at Work, European Journal of Work and Organizational Psychology, 5(2), 165-184.

4. Davenport, N., Schwartz, R. D., Elliott, G. P., 2003. Mobbing: İşyerinde Duygusal Taciz. (Mobbing: Emotional Abuse in the American workplace) (Translation: Osman C. ÖNERTOY). İstanbul: Sistem Yayıncılık.

5. Eser, O., 2008. Mobbing Kavramının Türkçe Serüveni. İstanbul Kültür Üniversitesi, http://turkoloji.cu.edu.tr/YENI\%20TURK\%20 DILI/ oktay_eser_mobbing_kavrami.pdf, [Erişim Tarihi: 28.04.2015].

6. Heinemann, P., 1972. Mobbing-Group violence by children and adults. Natur och Kultur, Stockholm.

7. Çobanoğlu, Ş., 2005. Mobbing: İşye Duygusal Saldırı ev Mücadele Yönter 1.Baskı, İstanbul, Timaş Yayınları: 26-27.

8. Çalışma ve Sosyal Güvenlik Bakanlığ Çalışma Genel Müdürlüğü (ÇSGB)., 2014. İşyerlerinde Psikolojik Taciz (Mobbing) Bilgilendirme Rehberi, Özel Matbaası, 2. Baskı, 45p., Ankara. 
